\title{
REMOTE SENSING-BASED WATER ACCOUNTING TO SUPPORT GOVERNANCE FOR GROUNDWATER MANAGEMENT FOR IRRIGATION IN LA MANCHA ORIENTAL AQUIFER, SPAIN
}

\author{
ALFONSO CALERA, JESÚS GARRIDO-RUBIO, MARIO BELMONTE, IRENE ARELLANO, \\ LORENA FRAILE, ISIDRO CAMPOS \& ANNA OSANN \\ Institute for Regional Development, University of Castilla-La Mancha, Spain
}

\begin{abstract}
Mapping irrigated surfaces and the crops growing on these surfaces by using Remote Sensing is a well known first relevant step to contribute to water governance at different scales ranging from farm, irrigation scheme and, by scaling-up, to the whole river basin. These maps provide a first estimation of the spatially distributed water flows about evapotranspiration and irrigation water requirements based on the cropping agronomic knowledge. During the last 20 years, annual maps of crops and irrigated surfaces elaborated by using time series of multispectral satellite imagery have been in the basis of a successful water management of a big groundwater body placed in the Southern Spain. Threatened by over-exploitation, this aquifer extends over around $10,000 \mathrm{~km}^{2}$ of land surface, in the middle Júcar river basin, supporting around 100,000 ha of irrigated crops, and providing drinking water for 150,000 inhabitants, with competing uses from downstream users. This paper describes the main learned lessons. In addition, the paper tackles a necessary further step in the context of the current requirements for water governance of this aquifer: the direct remote sensing-based water accounting, by quantifying agricultural water flows (e.g. rainfall, irrigation, evapotranspiration, drainage and recharge, at practical spatial and temporal scales for water governance purposes). This RS-based WA approach relies on dense time series of multispectral imagery acquired by the multisensor constellation formed by Landsat 8 and Sentinel-2, jointly with meteorological data. By this, we discuss the technical and non-technical feasibility to rely monitoring water abstraction on this RS-based WA approach, providing the basis for a hybrid system.
\end{abstract}

Keywords: remote sensing, water accounting, mapping, irrigated surfaces, irrigation.

\section{INTRODUCTION}

Agriculture is by far the sector with the greatest freshwater resources required for use in irrigated areas around the world. The high pressure on limited freshwater resources is further increased with additional demands from sectors such as urban, industrial, tourism and environmental conservation.

The management, use and distribution of water is one of the factors of potential conflict within a territory and between territories. In turn, in the last decades has emerged an intensive use of groundwater, which has been called by some authors as "silent revolution" [1], for which the management instruments developed mainly for surface water management have proved to be ineffective. To these challenges is added the impact of global warming that introduces additional uncertainties in the distribution and frequency of precipitation and drought, increasing the risk of desertification by the the depletion of renewable resources.

Thus, water management in agriculture faces important challenges and pressures. This management happens in different spatial areas: plot, farm, irrigated-scheme area and river basin. They are typical irrigation water management scales, and they correspond to different spatial scales, as well as they respond to different users and administrative ambits. Therefore, the scale or, more specifically, the delimitation of the system and the degree of aggregation chosen, are critical in the interpretation of water use and productivity. 
Water management should be supported by the basic principles of participation and transparency. By this way, the water managers can take into account the multiple aspects and interests to allow the cooperation of the different social actors involved. Participation requires that both administrations, irrigators and other stakeholders have to share adequate, good and up to date information on irrigated areas and water sources. They also have to participate in decision-making, establishing access to this information in a transparent way to other agents or social actors. Transparency must take place within a territory, but also of territories with others within the same river basin, and of basins with others. Such transparency requires mechanisms to be verifiable and generate confidence and security, in addition to laying the groundwork for conflict resolution by agreement. Irrigated area, water used in irrigation in a plot, in a farm, in an irrigation scheme, and in a river basin have should be known accurately for management purposes. In this way, so-called exploitation plans will be reliable and credible.

This paper describes the main learned lessons from a long-time experience on remote sensing-based water management in a big groundwater body placed in the southern Spain, in the middle Júcar River basin. Groundwater abstraction supplies fresh water for around 100,000 ha of irrigated crops, and provides drinking water for 150,000 inhabitants, with competing uses from downstream users. Besides this, this paper tackles a necessary further step in the context of the current requirements for water governance of this aquifer: the direct remote sensing-based water accounting, by quantifying agricultural water flows (e.g. rainfall, irrigation, evapotranspiration, drainage and recharge, at practical spatial and temporal scales for water governance purposes). This RS-based WA approach relies on dense time series of multispectral imagery acquired by the multisensor constellation formed by Landsat 8 and Sentinel-2, jointly with meteorological data. The goals of this paper are to address the assessment of the modelled water flows using RS against field data, and to discuss the technical and non-technical feasibility to relies monitoring water abstraction on this RS-based WA approach, providing the basis for a hybrid system.

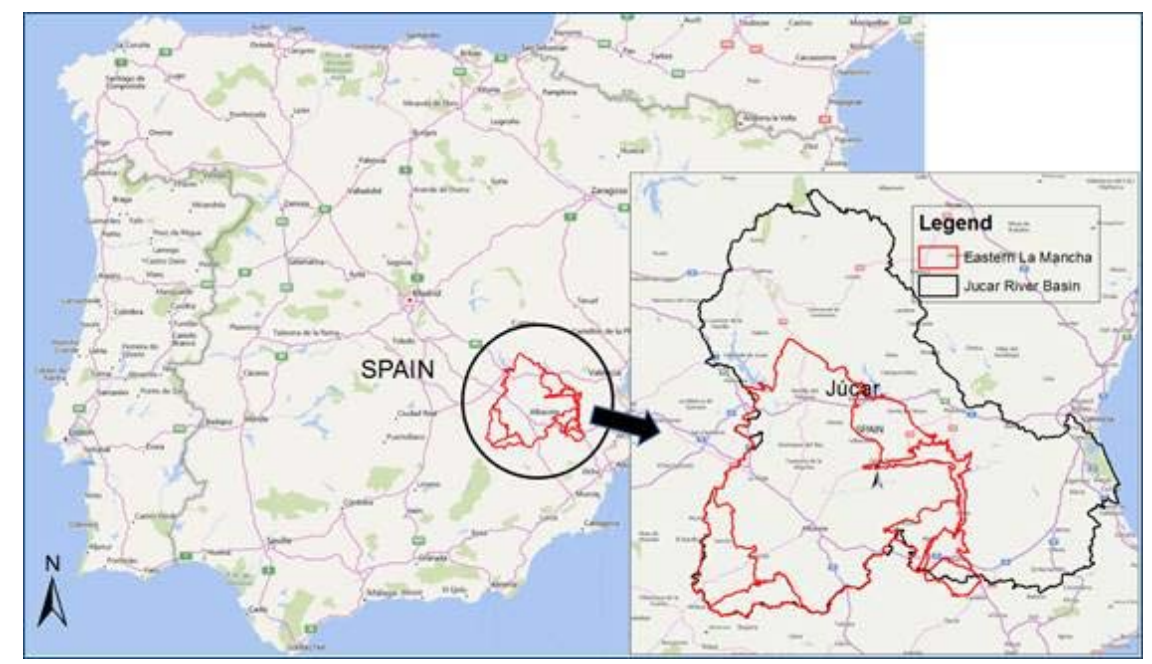

Figure 1: The Eastern La Mancha groundwater body delimitation is shown overlaid on the map of the Iberian Peninsula. This big groundwater body, around $10,000 \mathrm{~km}^{2}$ of land surface, is in the Jucar River basin, in the Southern of Spain. 


\section{EO-BASED MAPPING IRRIGATED SURFACES: THE MANCHA ORIENTAL EXPERIENCE}

Monitoring and mapping irrigated surface is a first basic element in the water management. If the classical monitoring by fieldwork inventory exhibits difficulties when delivery of water from surface reservoirs happens through well-known and mapped channels and ditches, the difficulty increases when water for irrigation abstracted from groundwater or from mixed surface-to-ground systems. In this case, monitoring requires a different approach than the traditional one, since repeated experience worldwide shows that the monitoring and control of irrigated areas from hundreds or thousands of wells can not be performed using traditional methods.

Mapping irrigated surface is probably the most classic of the applications of the Earth Observation in water management. It allows a digital thematic map to be obtained from satellite images that describes the spatial distribution of the different covers and/or uses standing in a certain area. In the case at hand, the focus is on the spatial distribution of irrigated crops. The detection of irrigated areas (defined as the identification of their location and their areal extent) requires land-use/land-cover maps that allow distinguishing irrigated from non-irrigated crops. One successful and widely used methodology consists of using a supervised "multi-temporal classification" based on a time series of EO images. These images provide the temporal evolution of the crops and vegetation during its growing season through time series of spectral reflectances, derived Vegetation Indices, (like NDVI, the Normalized Difference Vegetation Index, EVI, SAVI and others), and even, when available, surface temperature. The classification process based on temporal pattern recognition exploits the captured differences from the canopy on the above-mentioned parameters to assign each pixel to a vegetation class. These classes need to be defined on the basis of field work and knowledge about the crop phenology in a given area. This crop classification is the basis for identifying irrigated areas and when this irrigation happens.

This is the case of La Mancha Oriental aquifer. During the last 20 years, annual maps of crops and irrigated surfaces elaborated by using time series of multispectral satellite imagery have been in the basis of a successful water management of a big groundwater body placed in the southern Spain, as shown in Fig. 1. Threatened by overexploitation, this aquifer extends over around $10,000 \mathrm{~km}^{2}$ of land surface, in the middle Júcar river basin, supporting around 100,000 ha of irrigated crops, and providing drinking water for 150,000 inhabitants, with competing uses from downstream users.

In 1998, an agreement was signed between the water authorities, the Jucar River basin Authority [13], and the Eastern Mancha Users Central Board [14], for mapping irrigated areas by using remote sensing technique. Since then, annual maps of these irrigated areas, elaborated by the Remote Sensing Lab of University of Castilla La Mancha, have provided useful information for water management, water rights asignements, and sanctions. Temporal evolution of the irrigated surface (herbaceous crops) in hectares on the area delimited by the Eastern La Mancha groundwater body from 1982 year to actual is shown in Fig. 2.

Main characteristics of this long-time experience can be summarized as: Since 1998, annual maps showing the spatial distribution of irrigated crops have been elaborated. This irrigated area spreads in a disseminated way over an area of approximately 1 million hectares. The historical series analyzed started in 1982. Crop temporal pattern is the basic criteria to identify irrigated areas. A multitemporal sequence of images, of about 12-14 images per year distributed throughout the growing season, is currently used to obtain the irrigated crop map. Annual maps are posted on the CHJ website [13]. The multitemporal approach is able to distinguish between different crops according its main growing season, as shown in Fig. 2. 


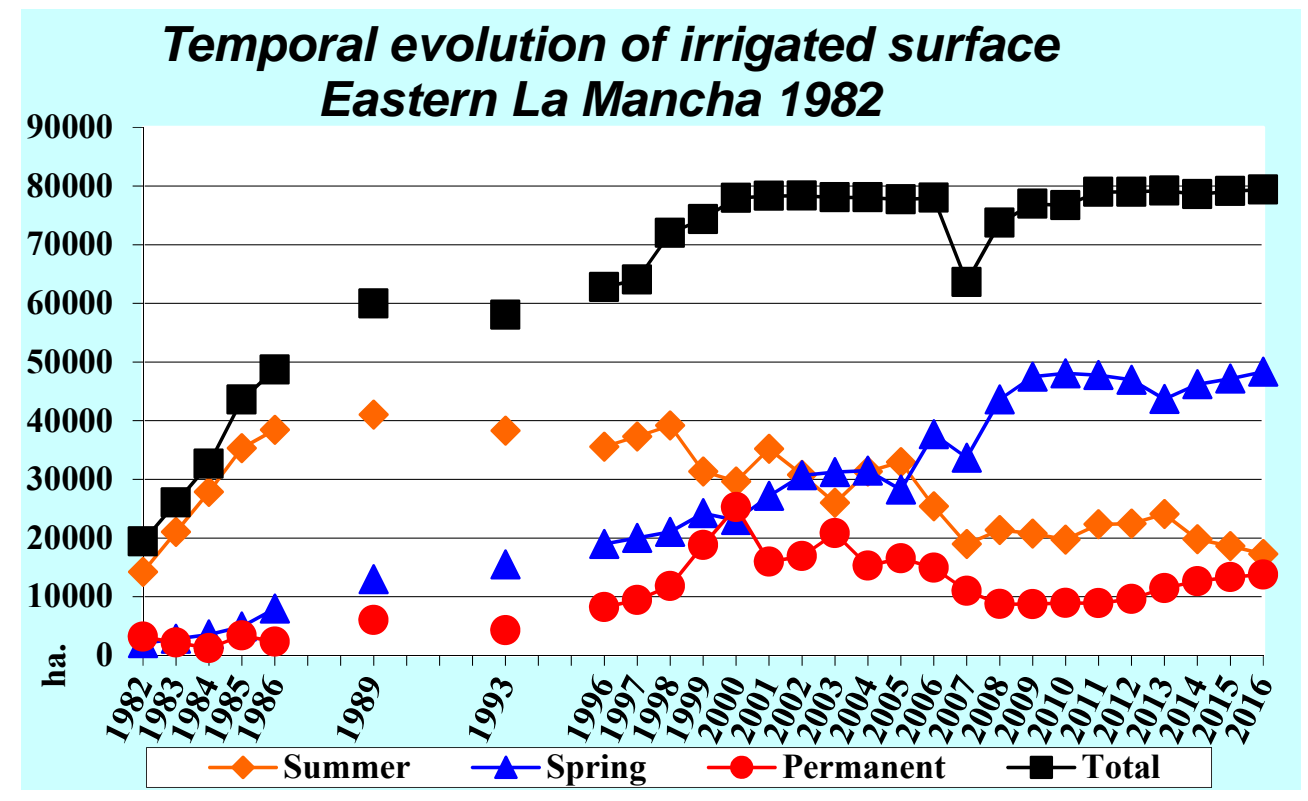

Figure 2: Temporal evolution of the irrigated surface (herbaceous crops) on the area delimited by the Eastern La Mancha groundwater body from 1982 to 2016. Mapping done by using time series of multispectral images during growing season. Different classes of crops identified according when its main growing season occur.

These maps of irrigated areas are shared by officials and representatives of farmers, each using such information for their own purposes and competencies. Sharing the base information is a crucial element for solving conflicts.

Development of a Satellite-Assisted Field Inspection. Images from satellite, obtained in real time, allow the comparisons of the crops previously declared on the Plan of Exploitation by farmers with those are currently growing. By this way, the official's ground inspection work is driven by the time series of satellite images and so more efficient field-work can be performed.

In the course of the years, irrigation rights have been regularized [2], by using the mentioned irrigated area maps, with agreement being around 95\%. In some cases, the disagreement has reached the courts; In May 2012 a Supreme Court ruling, ROJ: STS $3929 / 2012$, established the characteristics that the classification process based on satellite images needs to be considered as evidence, indicating the ERMOT project as a reference.

A "Jury of Irrigation" have been set up by farmers in agreement with the River basin Authority. This is a "first-stage" for sanctions and tries to solve those cases when the use of water in the campaign has been greater than authorized. A webGIS tool called SPIDER-ERMOT that allows visualisation of the crop development through the time series of images have proven to be very useful to provide evidence of what happened in the field. This tool can be accessed on line [15]. Fig. 3 shows a real case for a plot where several growing cycles occurred during 2016, meanwhile irrigation permission was only for one crop cycle. 


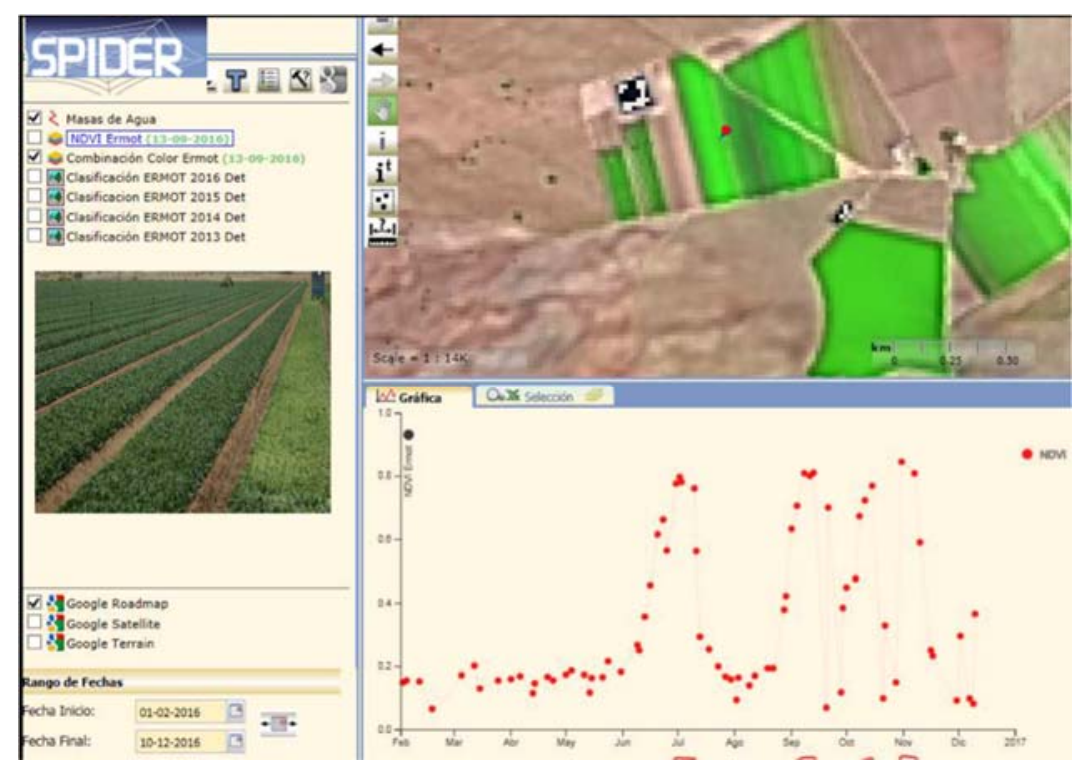

Figure 3: Crop development shows several growing cycles as it is described by NDVI time series during 2016 campaign, which can be accessed by SPIDER_ERMOT tool. This tool is used by the Jury of Irrigation to solve conflicts and sanctioning.

\section{MONITORING WATER ACCOUNTING FOR IRRIGATION: THE MANCHA ORIENTAL EXPERIENCE}

The traditional system for measuring and controlling the utilized water is to place flowmeters at each water source point. This classic and direct measurement has been widely used when the distribution is carried out from reservoirs through a network of channels. Although the same system has also been applied to groundwater systems, the implementation in large scales failed by the difficulty of not only the very expensive installation of these devices in thousands of wells, but also in their maintenance and monitoring. More difficulties to assure the water meter devices are working properly arise from the fact that the wells are located inside private properties, which must be accessed with permission of the owner.

An example of the implementation of flow meters in large-scale groundwater systems was the case of the High Guadiana river basin, in the Central Spain, very close to the Eastern Mancha. With the objective of monitoring and controlling groundwater withdrawals in the declared overexploited aquifers of the High Guadian river basin, the hydraulic administration invested a further $€ 6.5$ million over the period 1994-1996 to the installation of a network of 4,820 flow meters in wells [3]. Once the implementation of counters was done it was necessary to face the problem of maintenance, conservation and measurement of these devices. The economic valuation of these aspects is still difficult to assess. The conclusions recognize that "it is very difficult, if not impossible, that the hydraulic administration can manage a such system of direct measurement by counters". Although water meter technology is evolving quickly, some main barriers remain.

Taking it into account, the JCRMO, in agreement with CHJ, ruled to establish two parallel ways for monitoring water use. The first one is by using water meters. The second one is based on the identification of crop growing in each plot and assigning it a "mean" multiannual amount of water for irrigation, determined by the current agronomic knowledge. Therefore, 
once we have the irrigated crop map in a given area, we can determine the irrigation water requirements at different spatial scales [4]. Both systems for monitoring water use coexist today. Water managers prefer the allocation of consumption per crop and most of the farmers choose this system. But there is still no comparative analysis in detail about the performance and limitations of each of them.

\section{REMOTE SENSING BASED WATER ACCOUNTING FOR ESTIMATE IRRIGATION WATER REQUIREMENTS}

Water concession for irrigation purposes usually establishes the maximum amount of water that can be applied by the user for irrigation. Remote sensing addresses crop evapotranspiration, which is the water exchanged between the surface and the atmosphere. A water balance in the root soil layer links evapotranspiration with Irrigation Water Requirements, IWR. Water accounting methodology is based on a water balance approach where, based on conservation of mass, the sum of inflows must equal the sum outflows plus any change in storage.

The approach crop coefficient-reference evapotranspiration as described in FAO56 [5] is the most widely used and operationally mature method since 1970 s to retrieve evapotranspiration from agricultural crops. Time series of reflectances can be converted into maps of basal crop coefficient, what is analogous to a transpiration coefficient, which is the basic input in the widely used FAO56 model for crop evapotranspiration calculation. The crop coefficient can be obtained directly from linear relationships VI-based and/or from reflectance data and a series of intermediate relationships FAPAR or LAI-based, The degree of accuracy of both methods is similar [6]. Basal crop coefficient VI-based approach is operationally mature and can exploit spectral data from all sensors at higher spatial resolution to obtain dense time series of images.

Currently are in-orbit Landsat 8 and Sentinel-2 satellite constellation, providing free, at no cost, access to the suitable spectral imagery at $10 \mathrm{~m}$ (30 m for Landsat8) of spatial resolution. It enables a revisit time less than a week, being a definitive tool in this approach. Interpolation between consecutive images is used to fill gaps (e.g. due to cloud cover), then the product of basal crop coefficient and daily reference evapotranspiration from the agro-meteorological station provides daily crop water requirements in a pixel by pixel basis. Soil water balance using precipitation as input is able to obtain irrigation water requirements.

Remote sensing of evapotranspiration can also be calculated from surface temperature images by using other techniques like those based on surface energy balance [7], [8]. Given that of all current operational high-spatial resolution satellites only Landsat provides surface temperature, with a revisit time of 16 days, and in view of its spatial resolution in the thermal channel of $100 \mathrm{~m}$ pixel size, this procedure is complementary with that previously described, providing an independent quality control in suitable areas. The upcoming Sentinel-3 will also provide a thermal band, albeit at the coarse pixel resolution of $1 \mathrm{~km}$.

The approach reflectance-based crop coefficient jointly with reference evapotranspiration from meteorology station is able to determine accurately irrigation water requirements under optimal management. Some of the studied crops are cereals and vineyard [9]-[11]. Given we estimate with this approach the optimal IWR, if a farmer applies more water than needed, the excess water will drain or evaporate; otherwise, if a farmer applies less water than needed, the crop could develop some degree of water stress.

A dedicated software HidroMORE+ [12], has been developed for performing this soil water balance spatially distributed on large areas at pixel satellite size $(10 \mathrm{~m} \times 10 \mathrm{~m}$, in the case of Sentinel-2 as input) and daily scale. By this way we are able to estimate IWR at pixel 
scale and to aggregate it at the desired management scale (plot, farm, irrigation scheme, river basin).

Therefore, it appears technically feasible to implement a system EO-based for water accounting, coupled with networks of well-calibrated and maintained flow meters in representative locations for ground-truthing. It is a hybrid system. Nevertheless, demonstration projects are needed to asses the EO-based system in different environments and crops and to explore non-technical barriers like non-adapted rules and law to these methodologies.

\section{CONCLUSIONS AND PERSPECTIVES}

Water management in agriculture faces many challenges in different areas and scales, which become stronger in the case of intensive use of groundwater. One of the essential characteristics of an effective and lasting system of collective management of a common resource as water is the existence of an adequate structure for the monitoring and control of abstractions, which requires instruments capable of establishing an effective water management system. Repeated experience indicates that, without strict monitoring, supply policy means that demand is uncontrollably amplified.

Mapping irrigated areas by a dense time series of EO images at appropriate spatial and temporal scales has proven be a reliable tool for governance in large areas, increasing the efficiency of field work inspection. The constellation Landsat 8, Sentinel-2A and Sentinel-2B currently in orbit is able to provide enough free, at no cost, frequent and suitable imagery to describe the crop development. Further research could be conducted in order to improve the capability to identify irrigated areas, integrating all classification procedures to improve reliability of maps, by incorporating all EO and non-EO sources.

Remote sensing estimation of evapotranspiration, i.e. crop water requirements, based on crop coefficient estimates from multispectral imagery is mature and operational. A water balance in the root soil layer links evapotranspiration with Irrigation Water Requirements, IWR. Further investigation of relationship between basal crop coefficient and vegetation indices could be performed. Also, further studies on complementary aspects of water balance (NDVI)-based and energy balance (thermal)-based approaches to estimate crop evapotranspiration could help increase accuracy. Maps of reference evapotranspiration and past rainfall, which are based on meteorological data, could be improved by incorporating last advances of meteorological modelling research.

Better monitoring and mapping of water stress would also require additional research involving EO and non-EO aspects. EO could address mapping water stress by coupling actual ET estimates using recorded temperature and surface energy balance modelling together soil water balance fed by crop coefficients derived from multispectral imagery. Difficulties arise, however, on 3D crops with a large fraction of bare soil. Soil moisture estimates based on radar (e.g. Sentinel-1, SMOS or SMAP) could help improve accuracy, but need to be further developed for operational purposes.

In relation with governance aspects, further research needs concern the adequate governance types for the implementation of EO-based tools and services, for both mapping irrigated areas and monitoring abstraction to drive field inspections and eventually how to give legal force to the system for the EO-based classification and water abstraction to be used as legal evidence.

\section{ACKNOWLEDGEMENTS}

The experiences here described have been acquired in the course of a series of projects in which the authors have been involved, together with other teams, users and social actors, 
forming a large interdisciplinary team. This is the case of ERMOT project, funded by users, other Spanish national plan for Science like TESORO, MORE, and European projects like SIRIUS and the H2020 FATIMA.

\section{REFERENCES}

[1] Llamas, M. \& Martínez-Santos, P., Intensive groundwater use: silent revolution and potential source of social conflicts. Journal of Water Resources Planning and Management, 131(5), pp. 337-341, 2005.

[2] Ferrer, J. \& Gullón, N., Actuaciones de gestión y regularización administrativa en el acuífero de Mancha oriental. Presented at VIII Simposio de Hidrogeología de la Asociación Española de Hidrogeología, Zaragoza, Spain, 2004.

[3] Díaz-Mora, J., Experiencia de la instalación de contadores en los acuíferos de la cuenca alta del Guadiana. Medida y Evaluación de las Extracciones de Agua Subterránea, Sintesis y Conclusiones, ed. A. Ballester, J.A. Fernández \& J.A. López Geta, Madrid, pp. 141-160, 1999.

[4] Martín de Santa Olalla, F., Calera, A. \& Domínguez, A., Monitoring irrigation water use by combining Irrigation Advisory Service, and remotely sensed data with a geographic information system. Agricultural Water Management, 61(2), pp. 111-124, 2003.

[5] Allen, R.G., Raes, D. \& Smith, M., Crop evapotranspiration: Guidelines for computing crop requirements. Irrigation and Drainage Paper. 56, Rome, Italy, 1998.

[6] D’Urso, G. et al., Earth Observation products for operational irrigation management in the context of the PLEIADeS project. Agricultural Water Management, 98(2), pp. 271-282, 2010.

[7] Bastiaanssen, W.G.M., Menenti, M., Feddes, R.A. \& Holstlag, A.A.M., A remote sensing surface energy balance algorithm for land (SEBAL) 1. Formulation, Journal of Hydrology, 212-213, pp. 198-212, 1998.

[8] Bastiaanssen, W.G.M., Molden, D.J. \& Makin, I.W., Remote sensing for irrigated agriculture: examples from research and possible applications. Agricultural Water Management, 46(2), pp. 137-155, 2000.

[9] Torres, E.A.E, Modelo FAO-56 asistido por satélite en la estimación de la evapotranspiración en un cultivo bajo estrés hídrico y en suelo desnudo, $\mathrm{PhD}$ Thesis, Universidad de Castilla-La Mancha, 2010.

[10] Campos, I., Neale, C.M.U., Calera, A., Balbontin, C. \& González-Piqueras, J., Assesing satellite-based basal crop coefficients for irrigated grapes (Vitis vinifera L.). Agricultural Water Management, 98(1), pp. 45-54, 2010.

[11] Campos, I., Villodre, J., Carrara, A. \& Calera, A., Remote sensing-based soil water balance to estimate Mediterranean holm oak savanna (dehesa) evapotranspiration under water stress conditions. Journal of Hydrology, 494, pp. 1-9, 2013.

[12] Torres, E.A., Calera, A., Gonzalez-Piqueras, J., Rubio, E., Campos, I. \& Balbontin, C., Coupling remote sensing and FAO-56 for a distributed water budget model in large areas: HidroMORE. Remote Sensing and Hydrology, 352, pp. 401-405, 2012.

[13] CHJ, Confederación Hidrográfica del Júcar, in Spanish, Online. www.chj.es.

[14] JCRMO, Junta Central de Regantes de la Mancha Oriental, in Spanish, Online. www.jcrmo.org

[15] WebGIS, SPIDER-ERMOT, Online. http://maps.spiderwebgis.org/login/?custom= ermot. 